\title{
Impact of Distributed Generation on the Reliability of Local Distribution System
}

\author{
Sanaullah Ahmad \\ Electrical Engineering Department \\ IQRA National University (INU) \\ Peshawar,Pakistan \\ Sana Sardar \\ Electrical Engineering Department \\ IQRA National University (INU) \\ Peshawar,Pakistan
}

\author{
Azzam Ul Asar \\ Electrical Engineering Department \\ CECOS University \\ Peshawar,Pakistan \\ Babar Noor \\ Electrical Engineering Department \\ IQRA National University (INU) \\ Peshawar,Pakistan
}

\begin{abstract}
With the growth of distributed generation (DG) and renewable energy resources the power sector is becoming more sophisticated, distributed generation technologies with its diverse impacts on power system is becoming attractive area for researchers. Reliability is one of the vital area in electric power system which defines continuous supply of power and customer satisfaction. Around the world many power generation and distribution companies conduct reliability tests to ensure continues supply of power to its customers. Uttermost reliability problems in power system are due to distribution network. In this research reliability analysis of distribution system is done. The interruption frequency and interruption duration increases as the distance of load points increase from feeder. Injection of single DG unit into distribution system increase reliability of distribution system, injecting multiple DG at different locations and near to load points in distribution network further increases reliability of distribution system, while introducing multiple DG at single location improves reliability of distribution system. The reliability of distribution system remains unchanged while varying the size of DG unit. Different reliability tests were done to find the optimum location to plant DG in distribution system. For these analyses distribution feeder bus 2 of RBTS is selected as case study. The distribution feeder is modeled in ETAP, ETAP is software tool used for electrical power system modeling, analysis, design, optimization, operation, control, and automation. These results can be helpful for power utilities and power producer companies to conduct reliability tests and to properly utilize the distributed generation sources for future expansion of power systems.
\end{abstract}

Keywords-Electric power system reliability; distributed generation; reliability assessment

\section{INTRODUCTION}

The electricity demand is usually fulfilled by the power generated in electrical power plants. Fig. 1 shows a traditional power plant with the transmission and distribution section. The output power capacities depend upon size and type of generation. These capacities typically range from hundreds of MW to few GW [1]. Such large scale generating plants are located at a distance from load centers. Transmission lines and distribution feeders are used to transmit power from the point of generation to the load points [2], [3]. The fundamental characteristic of power system is to provide economical and

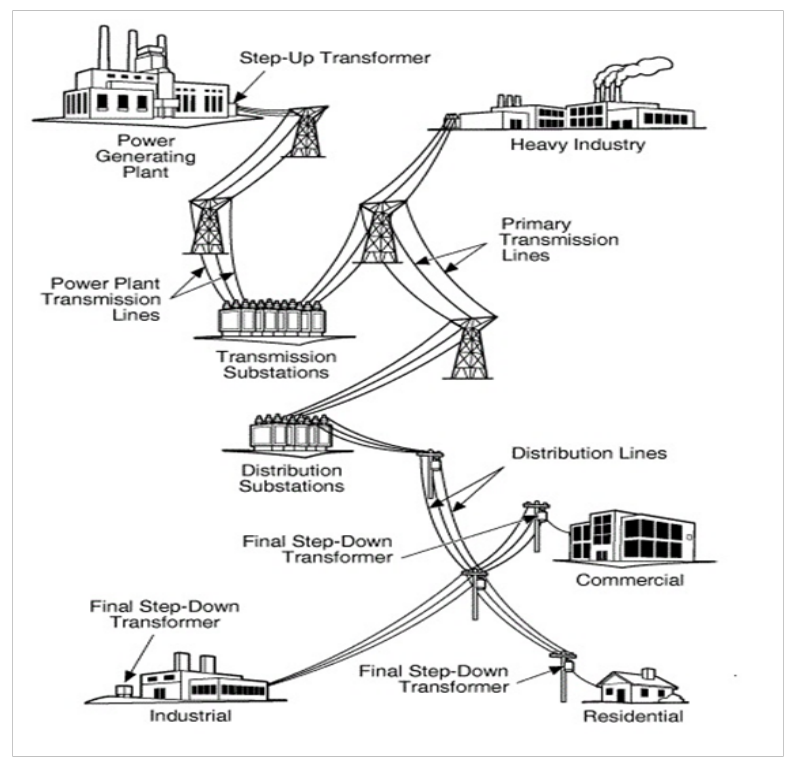

Fig. 1. Traditional Power System.

reliable electricity to its customers. Presently, the operation of power system is considerably influenced by energy obtained from renewable resources such as photovoltaic and wind energy system. The major challenges that electrical utilities are going through is to provide power to the customers with lower rates and by increasing the market value of services they provide with right amount of reliability and lowering the maintenance cost, operational and constructional cost [4]. Reliability is divided into system adequacy and security [5]. The adequacy is associated to meet the customer demand in the presence of sufficient electric power generation. The term security is associated to the capability of power system for its response to instability and transients that occurs in the system.

Distributed Generation is a new technique based on renewable energy resources which will possibly participate as a vital entity of electric Power System. Distributed Generation can also be considered as power generation unit injected to distribution network by neglecting the transmission lines, hence 
decreasing the technical losses [6], [7]. The power generated from these DGs is not connected to the national grids as they range from few kilowatts (KW) to several megawatts (MW) [8], [9]. Radial distribution systems are much modest but are more exposed to outages instead of interconnected system. During normal operating conditions the loads accomplish its required power demand, but if any fault occurs, the circuit trips causing failure to power flow. Despite the fact that distribution systems have localized effects, statistics shows that distribution system failure affects the system as much as 85 to 90 percent towards the unavailability of supply to load as compared with failure of other parts of electric power system [10]. Amalgamation of DG in the distribution system will provide an extra power for operation of loads even under faulty conditions. The placement of DG and protection devices will affect the reliability of system with respect to DG penetration [11].

Researchers are eager to develop such systems which are feasible, economical and time saving to cope with the increasing power demand and improve power system reliability. In this regard, distributed generation is considered to be the power paradigm for the new millennium. Distributed generation has a vital impact on power system, for this purpose, distributed generation source is connected to distribution system causing variation in power flow and reliability factors. This depends on the optimal location, size and number of distributed generation. Power generation and utility companies are looking for techniques to reduce costs and still provide the acceptable level of reliability necessary for the customers satisfaction. One solution is to add distributed generation with right configurations into distribution system. In this research the impact of distributed generation on the reliability of distribution system will be analyzed.

\section{Distributed Generation Technologies}

Energy resources are categorized as non-renewable (conventional) and renewable (non conventional) energy resources. Technologies based on renewable energy include PV modules, geo-thermal system and wind turbines. Where as co-generation plants, fuel cells and heat engines are the technologies based on non-conventional resources [12]. Fig. 2 shows different conventional and non-conventional energy resources are integrated with distribution system. In [13] a new plan is presented to solve the network re-configuration problem in the existence of distributed generation (DG) with an aim of minimizing losses in real power and voltage profile improvement in distribution system. In the existing power system the generated power is transmitted to load centers through long transmission lines, causing technical losses. These losses can be minimized by injecting the distributed generation near to load centers, eliminating transmission losses and hence improving the voltage profile. Many benefits have been derived from integration of DG units into the distribution networks by power system planners and policy makers [14]. These benefits depend upon the characteristics of DG units such as photovoltaic (PV), wind generating system and reciprocating engines, type of loads, local renewable sources and network pattern. This study comprehensively reviews various research works on the technical, environmental and economic benefits of renewable DG integration such as reduction in line-loss, reliability enhancement, economic benefits and optimizing environmental pollution. In [15], [16] the authors have discussed

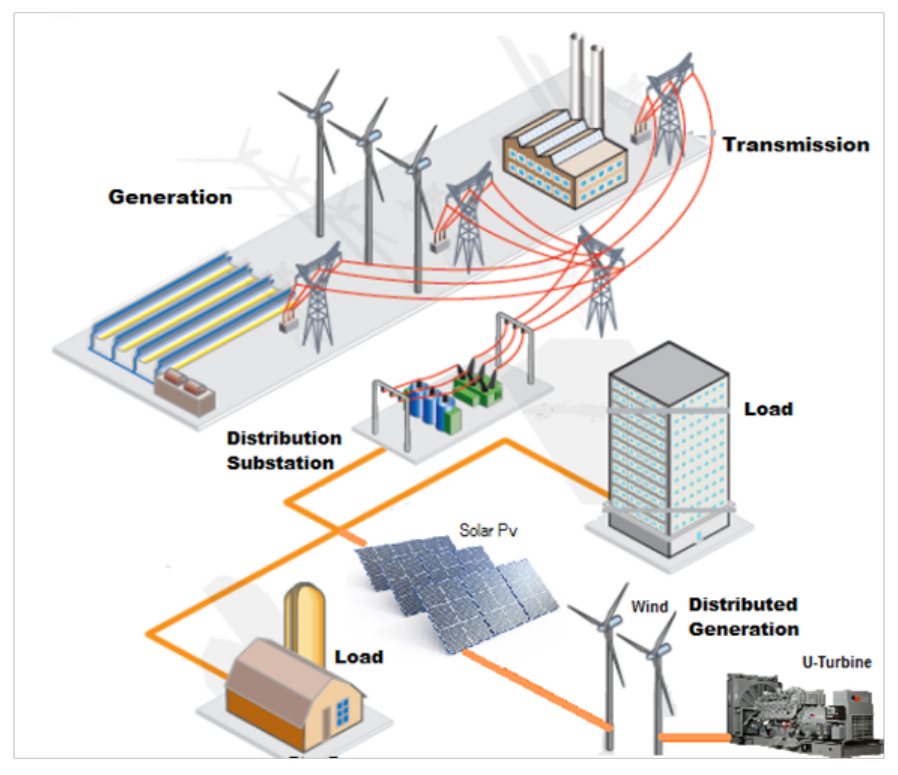

Fig. 2. Distribution System with Distributed Generation.

that maximum reliability improvement is obtained when the placement of Distributed generation is close to the customer premises, making available maximum access in provisions of customer numbers. The authors in [17] have shown that if the customer interruptions due to any fault in the system are followed by some planned techniques, likely by injecting DG units to the distribution system will improve the reliability of the system. The results reveal that the reliability of the distribution network does improve by injecting DG to the system.

\section{Reliability of ElECtric PoWer System}

The reliability of power has a great importance for its customers. The power quality issue can be defined by customer perspective as any state of supplied electricity that causes a fault in equipment or a device. Power reliability can be considered as a voltage quality. The utility can perform its duty utmost by providing a sufficient voltage to the customers. Utilities generally have no concern with the current obtained by the users at the end. For the perfect power quality it is necessary to have an ideal sinusoid with unvarying frequency and amplitude. When the source voltage is disturbed due to the transient character, its amplitude and frequency will be distorted. Due to this change low power quality will be obtained [18].

Generation stations comprises of different generating units which convert the mechanical energy to electrical energy by driving the turbine coupled with a generator. Steam is used to drive prime mover; this steam is formed inside boiler excited via natural gas, nuclear fuel, oil and coal. The capability of electricity generating plants is to supply continuous electricity that the customers require is submitted to as adequacy of system. System adequacy has the following basic conditions which if met, guarantee the system adequacy. In first condition 
the generating capacity of a plant should always be greater than system losses in addition to demand of the load.

\section{Generation capacity $>$ Demanded load+System losses}

For second condition the system should be able for the transportation of demand of the load to the consumer end without interrupting or overloading the equipments.

\section{Demanded load $\rightarrow$ Consumer end}

The third condition is to serve the consumer within a specific voltage range.

\section{Acceptable voltage range $\rightarrow$ Consumers served}

Distribution system falls just after the transmission system. Here, high voltages of the transmitted power are then stepped down to distribution level voltages, from where loads are served. Reliability has always been a secondary concern. However capacity planning is of main concern. A distribution system which is planned solely for capacity and least amount of protection standard, costs approximately 40 percent -50 percent of a usual overhead design. such system has no protection, absence of switching sections, tie switches are not present, no fuses and lack of lightning protection. Any capital spent ahead of such a minimal capacity design is spent for reliability improvement. Analyzing the viewpoint, approximately 50 percent of distribution systems expenditure is for capacity and 50 percent is for reliability. For residential consumers with 90 minutes of interrupted power/year, about 70 to 80 minutes will be attributable by distribution network [19].

Since past decades, less consideration to distribution network is established towards the reliability modeling and assessment of the electric power generating system. For measuring system performance, various measures of reliability have been defined by IEEE, these measures are actually done with reliability indices which includes frequency of outages, system availability, outage duration and response time. Some of these reliability indices are defined in [20].

\section{MATHEMATICAL MODELING AND EVALUATION OF POWER SYSTEM RELIABILITY.}

The techniques required for analyzing a distribution system is dependent upon type of system considered. The main concern of this chapter is to evaluate the basic techniques. These basic techniques are agreeable for analyzing radial distribution systems. However, some complex techniques are required for ring or meshed systems. Reliability studies are usually carried out assuming the generation and transmission system points, having infinite capacity and are 100 of reliable [21]. While discussing distribution systems, they may likely be radial networks or to some extent meshed networks [19]. In radial distribution system, components including over head lines, underground cables, bus bars and isolators are connected in series. In such system costumers could be connected to load point and need all the components to be operated.

\section{A. Components Modeling}

The indices in [20] are generally used to evaluate the distribution system's reliability indices illustrated below:

\section{Expected Failure Rate $(\lambda)$ :}

$(\lambda)$ is load interruption frequency. Expected failure rate is the sum of rate of

active failures $\left(\lambda_{a}\right)$ and passive failure $\left(\lambda_{b}\right)$. Equation is given below:

$$
\lambda=\lambda_{a}+\lambda_{b}
$$

In active failure rate the protective devices operates around the failed components i.e a short-circuit fault or the failure of component which restores after repair and replacement. While on the other hand, the protective device does not operate around a failed components in passive failure rate i.e an open circuit fault.

\section{Mean Time to Repair (MTTR):}

(r), is the time in hours, needed to restore a component outage to its normal operating condition is termed as Mean time to repair.

$$
\text { MTTR }=r
$$

\section{Expected Repair Rate $(\mu)$ :}

Expected repair rate is the frequency of repair and is denoted by $(\mu)$ (occurrence per year).

$$
\mu=8760 / \text { MTTR }
$$

\section{Mean Time to Failure (MTTF):}

Mean time to failure is probable time (in years) the component will remain in failed condition.

$$
\begin{gathered}
\text { MTTR }=\mathrm{m} \\
\mathrm{MTTF}=1 / \lambda
\end{gathered}
$$

\section{Mean Time Between Failures (MTBF):}

Mean time between failures is the expected time in years a component fails. Fig. 3 shows the difference between MTTR, MTTF and MTBF.

$$
\mathrm{MTBF}=\mathrm{MTTF}+\mathrm{MTTR} / 8760
$$

\section{B. Network Modeling:}

Physical networks are translated to reliability networks through network modeling, based on parallel and series configurations. Network modeling is not a state based technique but is a component base method. The two primary component configurations in network modeling are:

1) Series configuration.

2) Parallel configurations. 


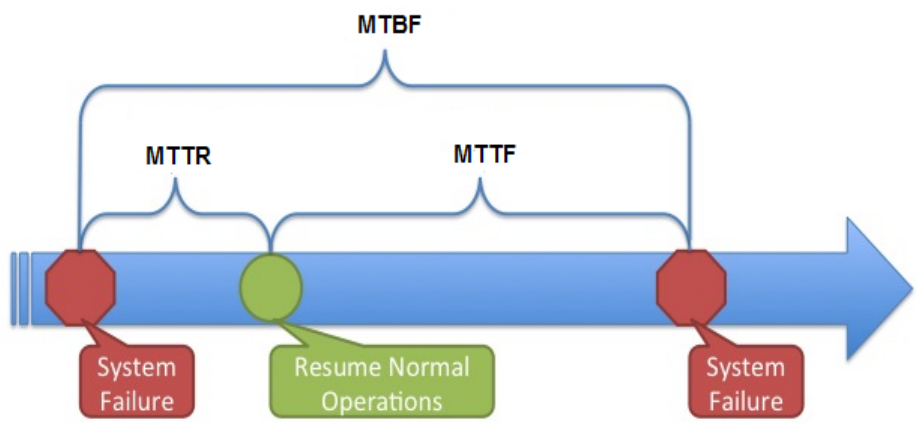

Fig. 3. MTTR, MTTF and MTBF.

1) Series Configuration: The series connection is shown below in Fig. 4 and 5:

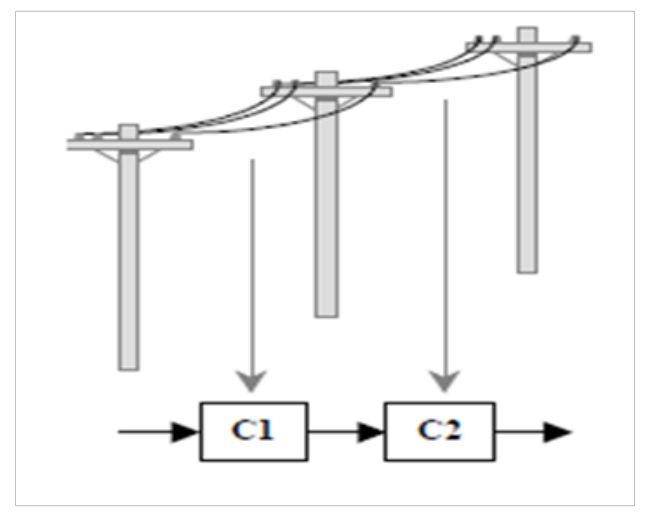

Fig. 4. Series Configuration of Network Modeling.

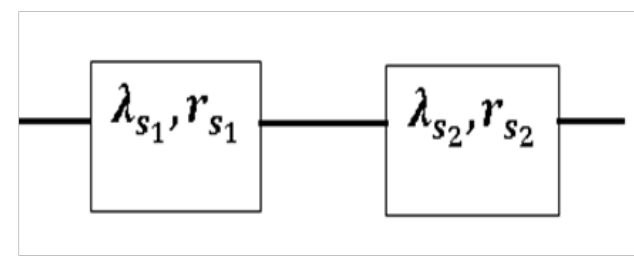

Fig. 5. Block diagram of Series Components.

$$
\begin{gathered}
\lambda_{\text {sysytem }}=\lambda_{s 1}+\lambda_{s 2}(1) \\
\gamma_{\text {system }}=\frac{\lambda_{s 1 * \gamma_{s 1}+\lambda_{s 2} * \lambda_{s 2}+\left(\lambda_{s 1} * \gamma_{s 1}\right)\left(\lambda_{s 2} * \gamma_{s 2}\right)}}{\lambda_{\text {system }}}
\end{gathered}
$$

2) Parallel Configuration: The parallel connection is shown in Fig. 6 and 7:

Fig. 8 shows how series and parallel components in a network are reduced.

$$
\begin{gathered}
\lambda_{\text {system }}=\frac{\lambda_{s 1} * \lambda_{s 2}\left(\gamma_{s 1}+\gamma_{s 2}\right)}{\left(1+\lambda_{s 1} * \gamma_{s 1}+\lambda_{s 2} * \gamma_{s 2}\right)} \\
\gamma_{\text {system }}=\frac{\gamma_{s 1} * \gamma_{s 2}}{\gamma_{s 1}+\gamma_{s 2}}
\end{gathered}
$$

$\lambda_{s 1}$ : failure rate of first series component.

$\lambda_{s 2}$ : failure rate of second series component.

$\lambda_{\text {system }}$ : failure rate of system.

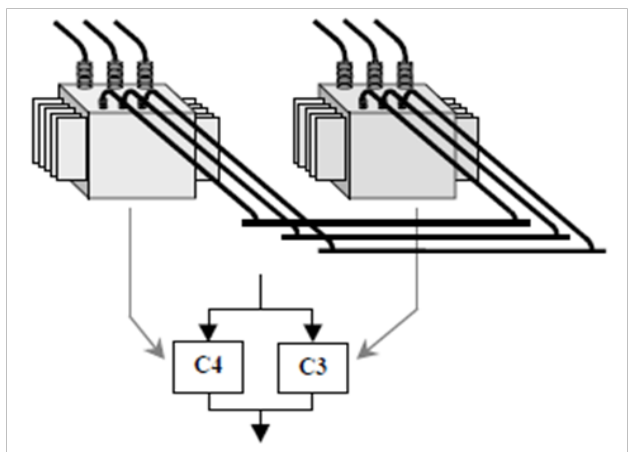

Fig. 6. Parallel Configuration of Network Modeling.

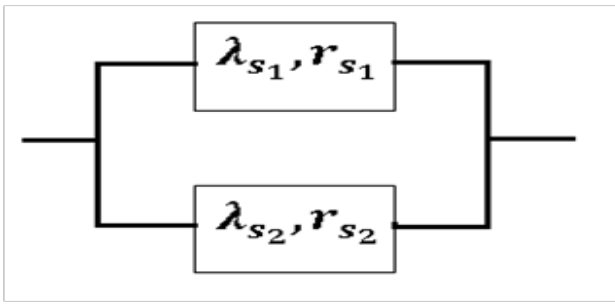

Fig. 7. Block diagram of Parallel Components.

$\gamma_{s 1}$ :outage duration of first series component.

$\gamma_{s 1}$ :outage duration of second series component.

$\gamma_{\text {system }}$ :outage duration of system.

Equation 01, 02, 03 and 04 are generally approximations and are applicable for component failure in transmission and distribution networks. These equations are universally used in reliability evaluation of distribution system [22].

In series network configuration, the probability of availability of path is equivalent to the multiplication of availabilities of individual component. In parallel networks, the probability of an unavailable pathway is equivalent to the multiplication of unavailability of the individual component.

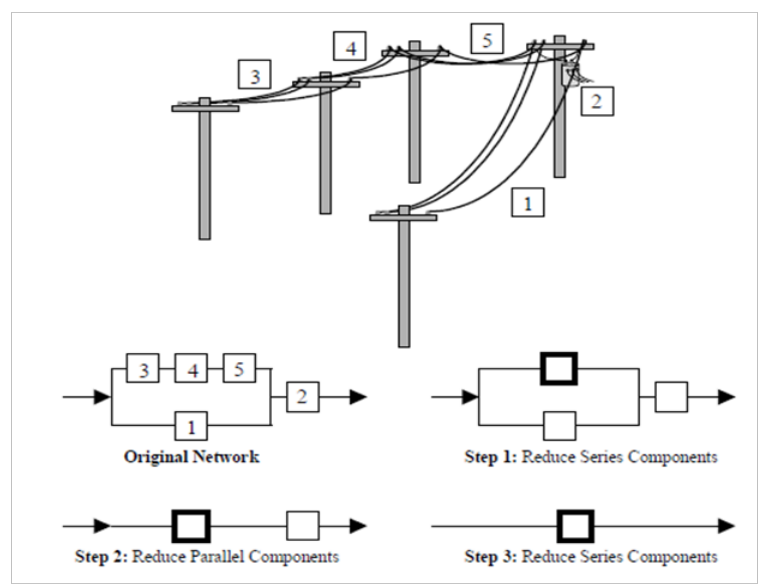

Fig. 8. Reduction of a Series and Parallel Component into Equivalent Network.

\section{System Modeling}

This research focuses on reliability model of radial distribution network, in which WTG, a DG source, is modeled as 
negative load for different reliability tests. However, several DG technologies either renewable or non-renewable energy resources can be modeled as voltage source and uninterrupted power source.

1) Modeling of DG Unit: Modeling DG as a negative load adding reactive power and real power into the network as shown in Fig. 9, whatever the system voltage is, this load will transport power to the system. Provided that DG is connected to a source, it will transfer power to the system in either peak hours or net metering mode. From viewpoint of utility, DG can be modeled as a negative load. While utilities will possibly need DG units for disconnecting it from the system when no utility source is connected, for ensuring safety, permitting faults to clear and avoiding the problems related with islanded operation.

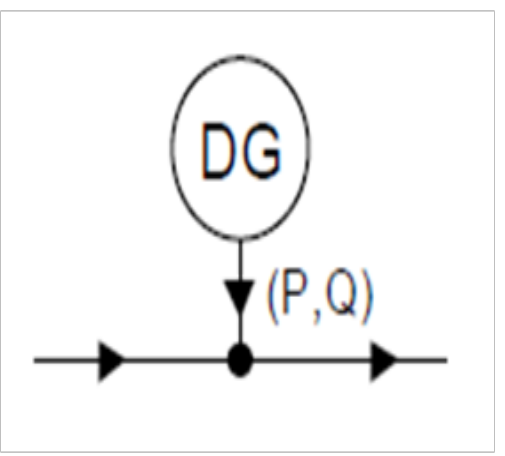

Fig. 9. DG as a Negative Load.

\section{Evaluation of Electric Power System RELIABILITY}

The Institute of Electrical and Electronic Engineers (IEEE) defines the generally accepted reliability indices in its standard number P1366, Guide for Electric Distribution Reliability Indices. IEEE-P1366 lists several important definitions for reliability including what are momentary interruption events, momentary interruptions and sustained interruptions[20]. These indices are classified as:

1) Load based (point) reliability indices.

2) System based reliability indices.

\section{A. Load Point Reliability Indices}

1) Average Failure Rate at Load Point $i, \lambda_{i}$ (failure per year)::

$$
\lambda_{i}=\sum_{j \in N_{e}} \lambda_{e, j}
$$

$\lambda_{i}=$ Average failure rate at point $\mathrm{i}$.

$\sum=$ Summation function.

$N_{e}=$ Total number of elements whose fault will interrupt load point i.

$\lambda_{e, j}=$ Average failure rate.
2) Annual Outage Duration at Load Point i, $U_{i}$ (hour per year):

$$
U_{i}=\sum_{j \in N_{e}} \lambda_{e, j} \cdot \gamma_{i, j}
$$

$U_{i}=$ Annual outage duration at load point $\mathrm{i}$.

$\sum=$ summation.

$\lambda_{e, j}=$ Average failure rate.

$N_{e}=$ Total number of elements whose fault will interrupt load point $\mathrm{i}$.

$\gamma_{i, j}=$ Failure duration at load point $\mathrm{i}$ due to a failed element $\mathrm{j}$.

3) Average Outage Duration at Load Point i, $r_{i}$ (hours):

$$
\begin{aligned}
& \text { Average outage duration at load point } i \\
& \gamma_{i}=\frac{\text { Annual outage duration at load point } i, U_{i}}{\text { Average failure rate at load point } i, \lambda_{i}}
\end{aligned}
$$

B. System based Indices

1) System Average Interruption Frequency Index (SAIFI):

$$
S A I F I=\frac{\sum\left(N_{i}\right)}{N_{T}}
$$

$\sum=$ Function used for summation.

$N_{i}=$ Total number of interrupted customers.

$N_{T}=$ Total number of customers served.

SAIFI can also be written as:

$$
S A I F I=\frac{S A I D I}{C A I D I}
$$

2) System Average Interruption Duration Index (SAIDI):

$$
S A I D I=\frac{\sum\left(\gamma_{i} * N_{i}\right)}{N_{T}}
$$

$S A I D I=$ System average interruption duration index.

$\sum=$ Function of summation.

$N_{i}=$ Total number of customers interrupted.

$N_{T}=$ Total number of customers served.

$\gamma_{i}=$ Restoration time in minutes.

3) Customer Average Interruption Duration Index (CAIDI):

$$
C A I D I=\frac{\sum\left(\gamma_{i} * N_{i}\right)}{N_{i}}
$$

$C A I D I=$ Customer average interruption duration index.

$\sum=$ Function of summation.

$N_{i}=$ Total number of customers interrupted.

$\gamma_{i}=$ Restoration time in minutes.

4) Average Service Availability Index (ASAI):

$$
A S A I=\frac{\text { (customer hours of availble service) }}{\text { Customer hours demanded }}
$$




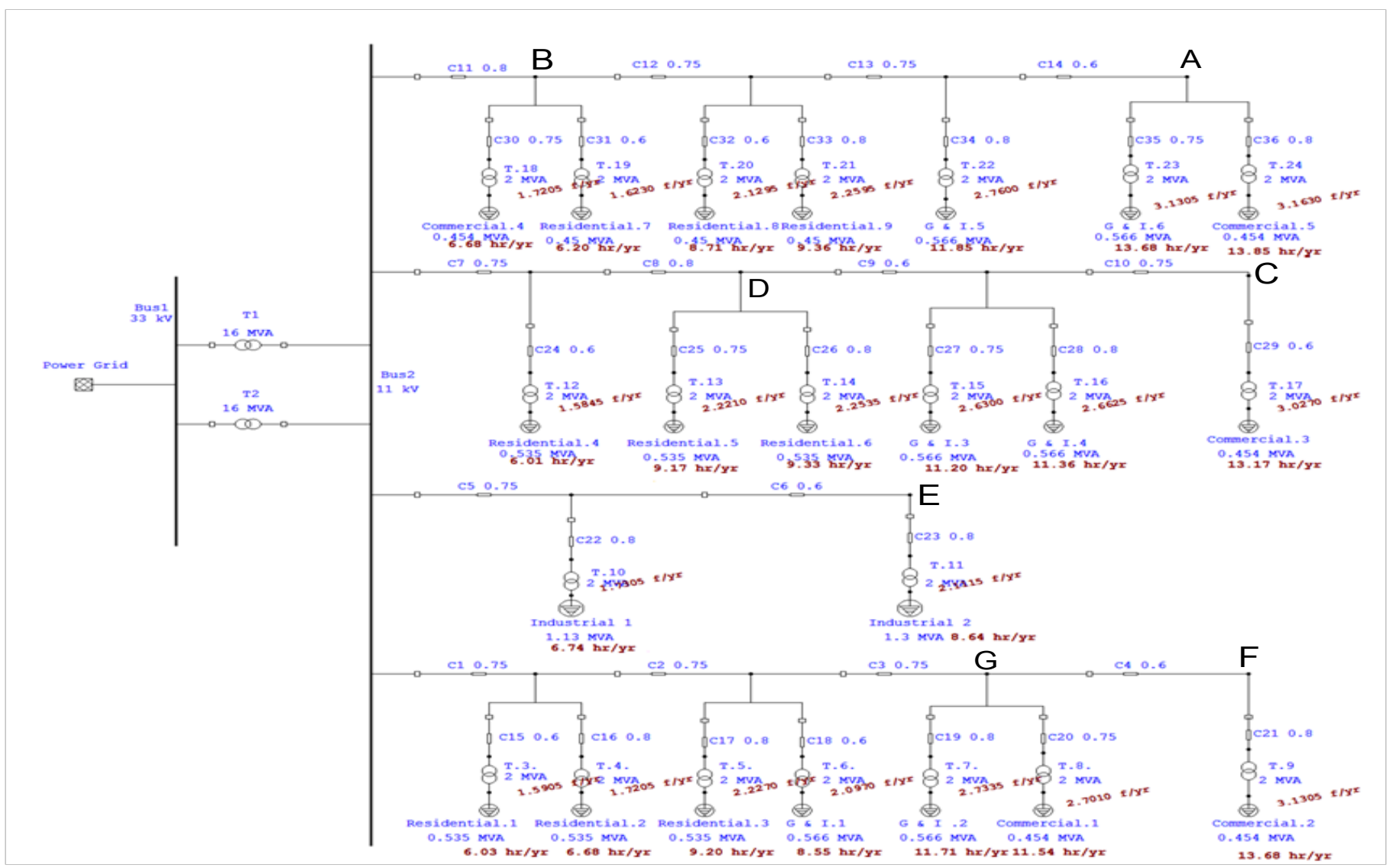

Fig. 10. RBTS bus 2 Modeled in ETAP.

5) Average service unavailability index (ASUI):

$$
A S U I=1-A S A I
$$

\section{Research Methodology}

The reliability evaluation of an electric power system is quite a tough job. For the ease of students to make hand calculations and to fully understand the reliability of power system including all the basic components, a test system by Roy Billinton was introduced for educational intention [23]. The distribution system developed by Roy Billinton Test System (RBTS) is used in this research. The RBTS is a six bus distribution test system, consists of two generator buses, five load buses, nine transmission lines, circuit breakers, connecting feeders/conductors, and eleven generation units.This work focuses on DG as a source rather than technology and is assumed that DG is used with its full capacity. Wind turbine generator of $1 \mathrm{MW}$ and $5 \mathrm{MW}$ are considered as DG source, Moreover DG is connected to distribution system with a circuit breaker in order to isolate DG in fault conditions. Reliability data of Wind turbine is based on operational observations.

\section{A. Modeling in ETAP}

ETAP software was selected for reliability analysis. Electric Transient Analysis Program (ETAP) is an electrical power system tool which has complete integration of $\mathrm{AC}$ and $\mathrm{DC}$ systems [24]. The reliability analysis by means of ETAP helps to evaluate distribution system reliability with extremely efficient analytical algorithms, for this purpose RBTS bus 2 as shown in Fig. 10 was modeled and analyzed in ETAP. Fig. 11 shows the flow chart that how results were calculated.

\section{RESUlTS AND DisCUSSION}

Under different scenarios six cases were analyzed which shows diverse impacts of DG on reliability, varying number, size and location of the DG unit(s) and its affect on the reliability of the traditional distribution system were analyzed.

1) Case 01: Reliability Analysis without DG: The data showed in Table 1 is the distance of different load points from feeder, annual outage rate, average outage duration and annual duration. The load near to the feeder experience lesser number of outage durations, on other hand, as the distance of load points increases from feeder the value of outage durations are also increased. This makes the system vulnerable to outages. Table 2 illustrates different system indices of the whole distribution system.

2) Case 02: Reliability Analysis with One DG: After injection of DG in distribution network at point A. The System Reliability indices shows improvement, as the interruption frequency and interruption duration is decreased as presented in Table 3.

3) Case 03: Impact of DG Size on Reliability: Varying the size of DG has no effect on system reliability indices as shown 
TABLE I. LOAD POINT INDICIES WITHOUT DG

\begin{tabular}{|c|c|c|c|c|c|}
\hline S.no & Type of customer & Distance from feeder. $(\mathrm{km})$ & Average outage rate. (f/ yr) & Average outage duration. (hr) & Annual outage duration.(hr/ yr) \\
\hline \multicolumn{6}{|c|}{ Residential } \\
\hline 1 & Residential 1 & 1.35 & 1.5905 & 3.79 & 6.0335 \\
\hline 2 & Residential 2 & 2.35 & 2.2535 & 4.14 & 9.3335 \\
\hline \multicolumn{6}{|c|}{ Commercial } \\
\hline 1 & Commercial 2 & 3.65 & 3.1305 & 4.37 & 13.6825 \\
\hline 2 & Commercial 4 & 1.55 & 1.7205 & 3.88 & 6.6835 \\
\hline 3 & Commercial 5 & 3.7 & 3.1630 & 4.38 & 13.8450 \\
\hline \multicolumn{6}{|c|}{ Industrial } \\
\hline 1 & Industrial 2 & 2.15 & 2.1115 & 4.09 & 8.6355 \\
\hline
\end{tabular}

TABLE IV. SyStem INDICES VARYING SIZE OF DG

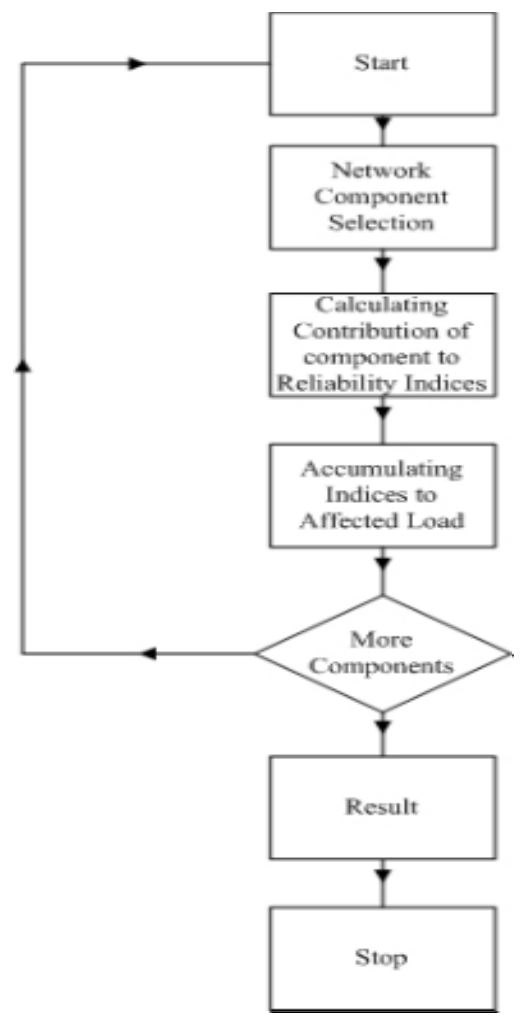

Fig. 11. Flow chart.

TABLE II. SySTEM INDICIES WITHOUT DG

\begin{tabular}{|c|c|c|}
\hline S no. & System indices & Results \\
\hline \hline 01 & SAIFI (f/ Customer. Yr) & 1.9772 \\
\hline 02 & SAIDI (hr/ Customer. Yr) & 7.9568 \\
\hline 03 & CAIDI (hr/ Customer interruption) & 4.0240 \\
\hline 04 & ASAI (pu) & 0.9991 \\
\hline 05 & ASUI (pu) & 0.00091 \\
\hline
\end{tabular}

TABLE III. System IndicES WITH ONE DG

\begin{tabular}{|c|c|c|}
\hline & At point 'A' & \\
\hline S no. & System indices & Results \\
\hline \hline 01 & SAIFI (f/ Customer. Yr) & 1.1979 \\
\hline 02 & SAIDI (hr/ Customer. Yr) & 6.0093 \\
\hline 03 & CAIDI (hr/ Customer interruption) & 5.016 \\
\hline 04 & ASAI (pu) & 0.9993 \\
\hline 05 & ASUI (pu) & 0.00069 \\
\hline
\end{tabular}

\begin{tabular}{|c|c|c|c|}
\hline & At point 'A' & & \\
\hline S no. & System indices & $1 \mathrm{MW}$ & $5 \mathrm{MW}$ \\
\hline \hline 01 & SAIFI (f/ Customer. Yr) & 1.1979 & 1.1979 \\
\hline 02 & SAIDI (hr/ Customer. Yr) & 6.0093 & 6.0093 \\
\hline 03 & CAIDI (hr/ Customer interruption) & 5.016 & 5.016 \\
\hline 04 & ASAI (pu) & 0.9993 & 0.9993 \\
\hline 05 & ASUI (pu) & 0.00069 & 0.00069 \\
\hline
\end{tabular}

TABLE V. System Indices AFTER INJECTING DG AT DIFFERENT LOCATION

\begin{tabular}{|c|c|c|c|c|c|}
\hline & SAIFI & SAIDI & CAIDI & ASAI $(\mathrm{pu})$ & ASUI $(\mathrm{pu})$ \\
\hline \hline Without DG & 1.9772 & 7.9568 & 4.024 & 0.9991 & 0.00091 \\
\hline At point A & 1.1979 & 6.0093 & 5.016 & 0.9993 & 0.00069 \\
\hline At point B & 1.3236 & 6.6311 & 5.010 & 0.9992 & 0.00076 \\
\hline At point C & 1.2041 & 6.0391 & 5.015 & 0.9993 & 0.00069 \\
\hline At point D & 1.2110 & 6.0721 & 5.014 & 0.9993 & 0.00069 \\
\hline At point E & 1.3290 & 6.6514 & 5.005 & 0.9992 & 0.00076 \\
\hline At point F & 1.2537 & 6.2863 & 5.014 & 0.9993 & 0.00072 \\
\hline At point G & 1.2564 & 6.2997 & 5.014 & 0.9993 & 0.00072 \\
\hline
\end{tabular}

in Table 4 the interruption frequency and interruption duration remains same while changing the capacity of DG unit.

4) Case 04: Injection at Different Locations (Optimum Location): DG has been injected at several different locations and system reliability indices have been recorded individually, Injecting DG at seven different locations in distributed network the indices showed that best or optimum location for injecting DG was Point A. The recorded indices are shown in Table 5.

5) Case 05: Multiple DG Injection at Same Location: Injecting multiple DGs at the same point (i.e point A). Not much variation in system reliability indices were observed comparing them with injection of single DG at same point. Table 6 illustrate this saying.

6) Case 06: Multiple DG injection at Different Locations: Multiple DG were injected at different locations and system reliability indices were recorded. The indices showed that system reliability indices were improved when the DG units were injected at two different point i.e point $\mathrm{A}$ and point $\mathrm{F}$. Table 7 depicts the recorded indices. -

TABLE VI. System Indices for Multiple DG Injection at SAme LOCATION

\begin{tabular}{|c|c|c|c|}
\hline \multicolumn{4}{|c|}{ At point 'A' } \\
\hline S no. & System indices & Single DG & Multiple DG \\
\hline \hline 01 & SAIFI (f/ Customer. Yr) & 1.1979 & 1.1980 \\
\hline 02 & SAIDI (hr/ Customer. Yr) & 6.0093 & 6.0095 \\
\hline 03 & CAIDI (hr/ Customer interruption) & 5.016 & 5.016 \\
\hline 04 & ASAI $(\mathrm{pu})$ & 0.9993 & 0.9993 \\
\hline 05 & ASUI $(\mathrm{pu})$ & 0.00069 & 0.00069 \\
\hline
\end{tabular}


TABLE VII SYSTEM INDICES FOR MULTIPLE DG INJECTION AT DIFFERENT LOCATIONS

\begin{tabular}{|c|c|c|c|}
\hline S no. & System indices & Multiple DG at Point A & DG at Point A \& F \\
\hline \hline 01 & SAIFI & 1.1980 & 1.1224 \\
\hline 02 & SAIDI & 6.0095 & 5.6428 \\
\hline 03 & CAIDI & 5.016 & 5.027 \\
\hline 04 & ASAI $(\mathrm{pu})$ & 0.9993 & 0.9994 \\
\hline 05 & ASUI $(\mathrm{pu})$ & 0.00069 & 0.00064 \\
\hline
\end{tabular}

\section{CONCLUSION}

Reliability assessment is the most vital element in planning and designing of distribution systems that must function in an economic way with minimum interruption of customer loads. With increase in distributed generation and renewable energy technologies researchers are more interested to analyze its effect on power systems.

In this research work the reliability analysis of radial distribution system with and without distributed generation has been done. The reliability indices depict that interruption frequency and interruption duration of load points were high as the distance of load point increases from feeder. A wind turbine generator as a distributed generation sources was injected in distributed system and different reliability tests were performed. The injection of one distributed generation unit near to load center has showed positive impacts on reliability, while injecting multiple distributed generations at different locations in distribution system has further increased the reliability of distribution system. Results showed that increasing the size of distributed generation Unit from $1 \mathrm{MW}$ to $5 \mathrm{MW}$ does not affect or change the reliability of distribution system. After caring out different reliability tests the optimum location was selected for DG unit to be planted.

From the results it can be concluded that proper injection of distributed generation into distribution system at a proper location increase the reliability of distribution system. Distribution system reliability can further be enhanced by injecting multiple distributed generations at different locations and near to load center $\mathrm{s}$ in distribution system.

\section{A. Future Work}

In future several DG technologies either renewable or nonrenewable energy sources can be modeled as voltage sources and uninterrupted power sources. This research work can also help distribution companies to evaluate the reliability of a real distribution network and also helps the DISCOs to inject distributed generation with most appropriate type, size and in proper location to enhance reliability of distribution system.

\section{REFERENCES}

[1] H. Iyer, S. Ray, and R. Ramakumar, "Assessment of distributed generation based on voltage profile improvement and line loss reduction," in 2005/2006 IEEE/PES Transmission and Distribution Conference and Exhibition. IEEE, 2006, pp. 1171-1176.

[2] P. Chiradeja and R. Ramakumar, "An approach to quantify the technical benefits of distributed generation," IEEE Transactions on energy conversion, vol. 19, no. 4, pp. 764-773, 2004.

[3] H. B. Puttgen, P. R. Macgregor, and F. C. Lambert, "Distributed generation: Semantic hype or the dawn of a new era?" IEEE power and energy magazine, vol. 1, no. 1, pp. 22-29, 2003.

[4] M. Čepin, Assessment of power system reliability: methods and applications. Springer Science \& Business Media, 2011.
[5] B. Roy, A. Ronald, and R. Norman, "Reliability evaluation of power systems," 1996.

[6] G. Pepermans, J. Driesen, D. Haeseldonckx, R. Belmans, and W. Dhaeseleer, "Distributed generation: definition, benefits and issues," Energy policy, vol. 33, no. 6, pp. 787-798, 2005.

[7] V. M. Quezada, J. R. Abbad, and T. G. S. Roman, "Assessment of energy distribution losses for increasing penetration of distributed generation," IEEE TRANSACTIONS ON POWER SYSTEMS PWRS, vol. 21, no. 2, p. 533, 2006.

[8] T. Q. D. Khoa, P. tt Binh et al., "Optimizing location and sizing of distributed generation in distribution systems," in 2006 IEEE PES Power Systems Conference and Exposition. IEEE, 2006, pp. 725-732.

[9] P. Dondi, D. Bayoumi, C. Haederli, D. Julian, and M. Suter, "Network integration of distributed power generation," Journal of power sources, vol. 106, no. 1, pp. 1-9, 2002.

[10] T. Dorji, "Reliability assessment of distribution systems," Master of Science in Electric Power Engineering, Norwegian University of Science and Technology, 2009.

[11] M. Al-Muhaini and G. T. Heydt, "Evaluating future power distribution system reliability including distributed generation," IEEE Transactions on Power Delivery, vol. 28, no. 4, pp. 2264-2272, 2013.

[12] A. A. Sahito, M. Uqaili, A. Larik, and M. A. Mahar, "Nonlinear controller design for buck converter to minimize transient disturbances," Science International, vol. 26, no. 3, pp. 1033-1037, 2014.

[13] A. Apparao and K. Bhashna, "Optimal allocation of dg considering loss minimization and voltage profile using pso."

[14] J. P. Lopes, N. Hatziargyriou, J. Mutale, P. Djapic, and N. Jenkins, "Integrating distributed generation into electric power systems: A review of drivers, challenges and opportunities," Electric power systems research, vol. 77, no. 9, pp. 1189-1203, 2007.

[15] B. Das, B. C. Deka, and C. Bimal, "Impact of distributed generation on reliability of distribution system," IOSR Journal Electrical and Electronics Engineering, vol. 8, no. 1, pp. 42-50, 2013.

[16] S. Ahmad, S. Sardar, B. Noor, and A. ul Asar, "Analyzing distributed generation impact on the reliability of electric distribution network," International Journal of Advanced Computer Science \& Applications, vol. 1, no. 7, pp. 217-221, 2016.

[17] P. Mazidi and G. Sreenivas, "Reliability assessment of a distributed generation connected distribution system," International Journal of Power System Operation and Energy Management (IJPSOEM), Nov, 2011.

[18] R. E. Brown, Electric power distribution reliability. CRC press, 2008.

[19] R. Billinton and S. Jonnavithula, "A test system for teaching overall power system reliability assessment," IEEE Transactions on Power Systems, vol. 11, no. 4, pp. 1670-1676, 1996.

[20] Transmission, D. Committee et al., "Ieee guide for electric power distribution reliability indices," IEEE Std 1366-2003, 2003.

[21] A. M. L. da Silva, A. M. Cassula, R. Billinton, and L. A. F. Manso, "Integrated reliability evaluation of generation, transmission and distribution systems," IEE Proceedings - Generation, Transmission and Distribution, vol. 149, no. 1, pp. 1-6, Jan 2002.

[22] R. Allan et al., Reliability evaluation of power systems. Springer Science \& Business Media, 2013

[23] R. Billinton, S. Kumar, N. Chowdhury, K. Chu, K. Debnath, L. Goel, E. Khan, P. Kos, G. Nourbakhsh, and J. Oteng-Adjei, "A reliability test system for educational purposes-basic data," IEEE Transactions on Power Systems, vol. 4, no. 3, pp. 1238-1244, 1989.

[24] "Etap," http://www.etap.com/, accessed: 2017-03-15. 